\title{
Some repeated inventory results of the Putorana plateau vascular flora
}

\author{
Igor N. Pospelov ${ }^{1, *}$, and Elena B. Pospelova ${ }^{1}$ \\ ${ }^{1}$ A.N. Severtsov Institute of Ecology and Evolution RAS, 119071 Moscow, Russia
}

\begin{abstract}
Resulting generalization of herbarium and literature data and our own observations, a list of vascular plants growing on Putorana plateau territory was compiled, including 736 species (without adventive). The history of the plateau flora study since the 70 s of the last century is described. The analysis of geographical and ecological-coenotic structure of the flora is carried out, according to the results of which it can be attributed to the hypoarctic type. The cluster analysis of the flora let to distinguish 3 clusters within the territory - the eastern one, with the flora of the moderately hypoarctic subtype, the central one and the southwestern one, the flora of which belongs to the hypoarcto-boreal subtype. Considerations concerning the history of the formation of the plateau flora are presented. Plant invasion on the Putorana plateau occurred both from the north, where Arctic species penetrated into the highlands, and from the south and west - these are boreal species mainly of the Eurasian and Asian fractions. A certain role in the formation of the flora is played by historical factors, especially the impact of the occurrence and melting of glaciations, which differ in different parts of the plateau.
\end{abstract}

\section{Introduction}

The plateau flora was completely unexplored until the 70s of the last century. The first expedition aimed at studying flora of the plateau was conducted in 1968-72 by botanists of Plant Physiology and Biochemistry Siberian Institute. The survey of plateau vascular flora was carried out by the method of specific floras and grid floral mapping. The results of these studies were published in the monograph "Flora of Putorana" [1]. The resulting list comprised 569 species and subspecies of vascular plants, including some ruderal species from the vicinity of Norilsk. It was this list that served as the basis for further floristic works on the plateau. However, an analysis of the list, compiled almost 50 years ago, revealed that it needs some adjustment. First, not all the sites surveyed by the authors belong to the territory of the Putorana plateau proper. In particular, the Haya-Kuel site, which is characterized by specific calcifilic flora, is already located on the territory of the Kotui plateau, which is composed of limestone. In this area alone, the authors collected 28 calcifilous species distributed east of Putorana, mainly in the mountains of the AnabarKotui mountain massif. After excluding them from the list, the real volume of the latter is 541 taxa. In addition, during monograph writing, only finds confirmed by herbarium

\footnotetext{
*Corresponding author: pleuropogon@gmail.com
} 
collections were used, which in some places led to a noticeable incompleteness of the lists. Nevertheless, its authors were the discoverers of the flora of Putorana, and if the lists they received in some cases were not always complete enough, then this is quite understandable - after all, it was the first time they had come to a completely unexplored place with unfamiliar flora. In addition, the cartographic support in those years was not large-scale enough. Some insufficiently complete identification of the flora was associated with these reasons.

Almost at the same time (1968-77), the flora of the plateau southern part in the basins of Kureika and Lower Tunguska rivers was studied by V. B. Kuvaev, who noted 412 species [2]. In the extreme west of the plateau in 1975, A. P. Tyrtikov examined the flora of the lower course of Khantaika River in the area of the exit from the mountains. Unfortunately, the resulting list has not been published, but the MW Herbarium stores its collections with exact references - 185 species ( 27 - not specified by previous authors). Since the end of 80 's, the study of territory flora has significantly intensified, and publications have appeared that list the local flora of the northwestern part of the plateau (the vicinity of lakes Lama, Sobaczye, Kapczuk, Ayan, etc.).) [3, 4, 5, 6]. By the early 2000s, the general list of plateau flora included, thus, about 670 species.

\section{Materials and Methods}

Since 2015, the authors of this report have started a project to re-inventory the flora of Putorana. Actually, we examined 6 key sites, of which 3 were located at the points indicated in the "Flora of Putorana" [1] - Lakes Kutaramakan, Ayan and the Imangda River. Partial surveys of the surroundings of the city of Talnakh (the "Red Stones" nature monument) were also carried out. The field work by the authors was carried out using the method of local floras, as well as by previous researchers. But at the same time, the laying of routes was carried out according to the contours previously identified on the landscape map, compiled using large-scale satellite images. This approach was used earlier in the study of the flora of the tundra zone of Taimyr and the mountains of the Anabar-Kotui massif. It allows to fully cover most fully all ecotopes available on the territory. As experience has shown, this significantly increases the effectiveness of the survey: for example, in the re-surveyed areas, the list of flora exceeded the primary one by sometimes $30-40 \%$. The reason for this can hardly be only an actual increase in floral diversity, most likely, during the initial survey using only a topographic basis, subtle ecotopes with a peculiar flora that were not included in the scale of the maps, but were clearly distinguishable in the images, could be missed. During 5 field seasons, we identified 60 species that were not previously listed for the Putorana plateau, including Botrychium multifidum, Carex spaniocarpa, Rumex aureostygmaticus, Oxytropis czekanowskii, O. tichomirovii, Taraxacum byrrangicum, which were included in Krasnoyarsk Territory Red Book, as well as the locations of Ranunculus pallasii, Thalictrum foetidum, Potentilla pulviniformis, $P$. subvahliana etc., which are the most remote from the main area. [7, 8].

\section{Results and discussion}

Our main task was to compare consolidated list of vascular plants collected in different years on the plateau territory. It includes all the species listed in the available publications, materials from the Herbariums MW, NSK, partly-LE, and the results of our own observations. The main difficulty with compiling the list was the diversification of observations, since the taxonomy of many species has undergone a number of changes in recent years. For this reason, when reducing the list to modern names, some taxa have 
changed their status, sometimes repeatedly. As a basis, we took the list of Russian flora by S. K. Cherepanov [9], but with some changes adopted in recent monographs on individual groups of plants.

The resulting list includes 736 species (excluding 19 adventitious) from 73 families and 238 genera, distributed from the northern tip of the mountain system to a latitude of about $70^{\circ}$ in the south; information about more southern flora within the plateau, unfortunately, is not available. The full list is being prepared for publication in the monograph. The analysis of flora geographical structure as a whole showed approximately equal proportions of the arctic (32\%) and boreal (37\%) latitudinal fractions, with a smaller proportion of the hypoarctic $(28 \%)$, significantly less plurizonal. There are similar trends in the ratio of longitude fractions -with the overall predominance of the circumpolar fraction (39\%), the species of Asian $(33 \%)$ and Eurasian (25\%) are almost equally distributed, and the share of mainly American is negligible. The ecologico-coenotic structure of the flora is not so uniform - the species of shrub-meadow $(25 \%)$ and tundra (20\%) landscape-phytocenotic suits (later: suits) predominate; the others suites - mountain and forest (16 and $17 \%$, respectively), bogs $(10 \%)$, erosiophilic $(8 \%)$ and aquatic $(4 \%)$ suites. We conducted a cluster analysis of local floras, based on the above-mentioned literary and author's sources.

The similarity in the Otiai coefficient and the nearest neighbor method were used in the construction. The most complete lists were selected for analysis to exclude artifacts. The dendrogram below shows quite well the boundaries that divide the entire array into 3 large clusters (Fig. 1). The entire set of local floras is clearly (at the level of $40 \%$ ) divided into 3 clusters, including local floras, conditionally located east (I) and west (II, III) of the watershed of the Yenisei-Pyasina and Kheta-Khatanga river systems (Fig. 2).

Cluster I includes the local floras of key sites located in the eastern and southeastern parts of plateau. This is mainly a high-altitude area, its flora is 496 species. Its composition is dominated by the arctic fraction $(47 \%)$, with a low value of boreal $(23 \%)$ and hypoarctic $(24 \%)$. Based on this ratio of latitudinal fractions, the flora of the cluster as a whole can be attributed to the moderate-hypoarctic subtype of the hypoarctic type. Nevertheless, this ratio differs in different areas - to the south, the role of arctic and boreal species significantly decreases and increases. The latitudinal structure also corresponds to the ratio of different suits species - with some predominance of tundra (40\%) and mountain (19\%) species, quite a few forest $(9 \%)$ and bog $(8 \%)$ species. The longitude structure of the eastern cluster flora is quite typical of the Putorana flora as a whole. The eastern cluster (I) can be divided into several small sectors:

- northern, high-altitude (Lake Bogatyr, Negu-Iken), heights of 1000-1500 m above sea level. The forest belt in the surveyed territories is practically absent (it is developed in the lower zones, where the authors did not collect data), mountain tundras predominate, and cold mountain deserts occupy a large area. The composition of the flora is strongly dominated by the arctic fraction (70 \%), boreal - about $10 \%$; and among the suits - tundra $(52 \%)$ and mountain $(25 \%)$. Due to this, the flora is very poor - only about. 200 species;

- central, medium-high mountain (Lake Ayan), heights of 500-1600 m above sea level. All high-altitude belts are developed, with the predominance species of arctic (41\%) and boreal fractions (about 25\%) in the flora, the tundra suite $(46 \%)$ is still high, but part of the shrubs-meadow suite is also significant $(22 \%)$. The flora richness is much higher -424 species; this is a consequence of a more diverse landscape structure; 


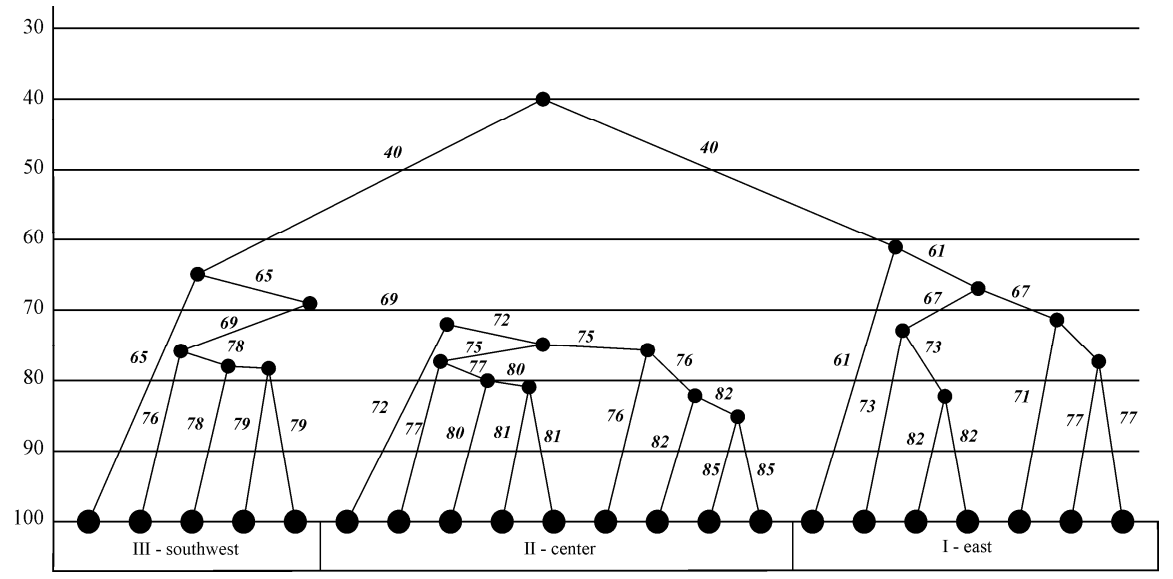

Fig. 1. Dendrogram of the similarity of local floras by species composition

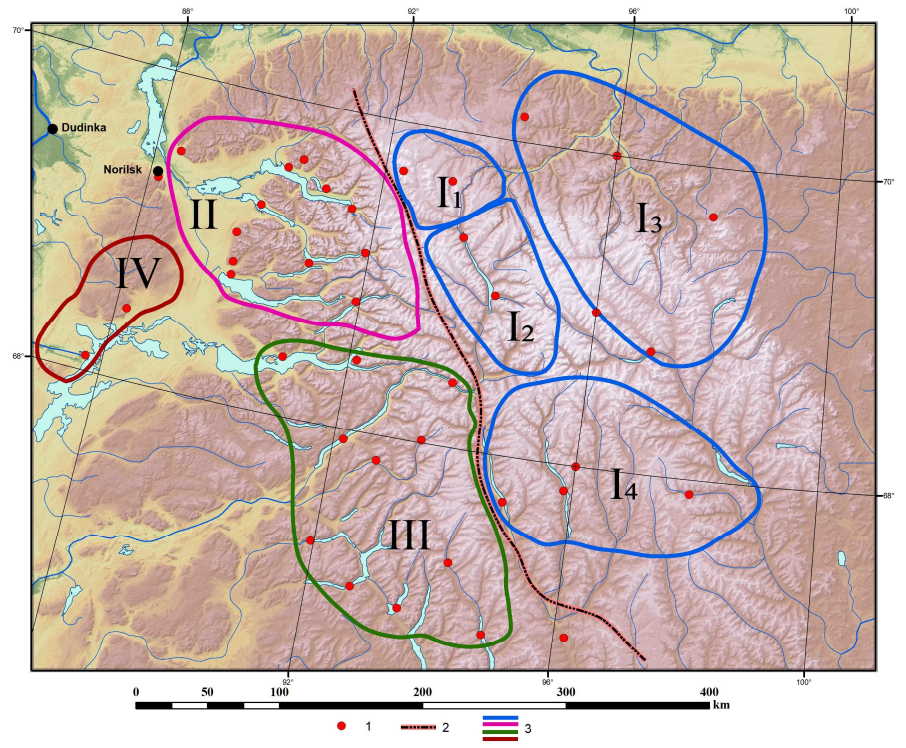

Fig. 2. Schematic map of the location of clusters on the ground and their structure. 1 - local floras; 2 - conditional boundary between the basins of the Yenisei-Pyasina and Kheta-Khatanga rivers; 3 clusters borders (color corresponds to the cluster)

- north-eastern, mountainous, with altitudes of $700-1500 \mathrm{~m}$, poorly studied, all data are given on the " Flora of Putorana "[1] - Lake. Baselak, Bokovoe, Harpicha. The total richness of the flora is 350 species, but most likely, the flora of the sites is not fully identified. The species of the arctic fraction make up 50\%, the proportion of boreal is about the same $(24 \%)$. Just as in the central subcluster, tundra (41\%) and mountain (20\%) suits predominate, but the share of shrubs-meadow formations is also higher-20\%;

- south-eastern, mid-mountain (Lakes Beldunchana, Anama, Hakoma), 300-1000 m above sea level, lies in the Kureika river basin. Like the previous one, this area is poorly studied, according to the Flora of Putorana [1] there are 326 species, although judging by the nature of the vegetation, there should be much more of them. The share of species of the arctic fraction is reduced (38\%), but the maximum for the entire east of the boreal fraction is $34 \%$. Significantly lower participation in the flora of the tundra suite (only $29 \%$ ), shrubs- 
meadow $-24 \%$. Species of Forest suite account for $14 \%$, which is more than in other sectors of the eastern cluster.

According to the ratio of latitudinal fractions, the flora of the eastern cluster as a whole can be attributed to the moderately hypoarctic subtype of the hypoarctic type.

Cluster II covers areas located in the northwestern part of the plateau. This is the most well-surveyed area, with 635 species recorded at 12 key-plots. The territory is middlemountais, it contains most of the braking Large Norilsk lakes (Glubokoe, Lama, Sobaczje, Kutaramakan, Keta), with altitudes ranging from 50 to $1200-1300$ m, parts of the NorilskRybninskaya depression partially enter it. The vegetation is characterized by vertical zoning, and communities are represented from closed forests to areas of cold mountain deserts. The nature of the flora differs significantly from cluster I - at this cluster there are in 1.5 times lower species of the arctic fraction (30\%), and, on the contrary, much higher boreal $(41 \%)$, i.e. it can be attributed to the hypoarctic-boreal subtype of the hypoarctic type. This is also consistent with the distribution of the share of species from different suits - the majority of boreal species are concentrated in shrub-meadow (23\%), water (4\% - the highest values in the entire territory!), bog and forest formations. This is resulted by wide distribution of near-lake ecosystems with extensive meadows, shrubs and swamps, as well as higher forested areas - the forests are mostly larch, sometimes spruce-larch, sometimes pure spruce forests. In the sub-holtsy belt - alder shrubs, birch elfin woodlands, above mountain tundra, sometimes at high levels - fragments of cold mountain deserts.

Cluster III, southwest, is located in the south of previous one in the basins of the Khantyka and Kureika rivers, which flow into the Yenisei River. Altitudes range from 70 (Lake Khantayskoe) to $1250 \mathrm{~m}$. The territory is also full of lakes, but their type is somewhat different - they are long, broken (Dupkun, Ende, Nyakshingda, Upper and Lower Tembenchi), with narrow, often canyon-like river valleys flowing into them. The forest belt is developed up to 600-650 m, the forests are mainly larch, green mossy, on the upper border of the forest - birch elfin woodlands. The subholz light forest and alder shrubs are more developed, and the rocky and spotted dryad -lichen and dryad-sedge-moss tundras are even higher. The belt of cold mountain deserts is absent, or weakly expressed. The geographical and ecological-coenotic structure of the flora differs from the previous clusters, especially from the eastern one. The proportion of species of the boreal fraction is high (together with the arctoboreal group - almost $32 \%$ ), with smaller proportions of the hypo-arctic and arctic fractions, i.e. the flora of this territory can be attributed to the boreal type. Among the longitude fractions, with the expected predominance of the circumpolar fraction, the most significant share is euroasian (31\%), asian slightly less (22\%). It is result of active penetration of western preference species from the Yenisei valley. The shares of the suite - tundra, shrub-meadow and forest are approximately in the same proportion, but it should be noted that these discrepancies can be attributed to the incomplete identification of the flora.

\section{Conclusion}

The high diversity of the physiographic conditions of territory stretching from north to south for more than $400 \mathrm{~km}$, the significant range of heights and the difference in mesoclimates cause the heterogeneity of the ecologo-coenotic composition of its flora. At the same time, the uniform distribution of geoelements may indicate that the plantsettlement of the Putorana plateau occurred both from the north, where arctic species penetrated into the highlands (see - cluster I), and from the south and west - these are boreal species of the mainly eurasian fraction (see-cluster III) or boreal Asian (see cluster II). It is on the Putorana plateau that the border of the Hypoarctic and Boreal floral belts passes, but if B. A. Yurtsev [10] draws the southern border of the Hypoarctic belt south of 
the Arctic Circle $\left(66^{\circ} 30^{\prime}\right)$, then according to the results of our analysis of the flora structure, it can be assumed that it runs $1.5-2^{\circ}$ north, approximately along the general watershed of the Yenisei and Kotui-Khatanga river basins (i.e., the south-eastern subcluster of cluster I and almost the entire cluster III are located south of this border).

In many respects, the differences in flora and vegetation of the western and eastern sectors of Putorana are also related to historical reasons, in particular, the age of the formation of mountain ranges and the impact of subsequent glaciations. The Putorana plateau has been repeatedly subjected to glaciation, with the northern part of the plateau being the most affected, while the mountain-valley and corrie glacier types of glaciation developed in the northwest [11]. According to our earlier convergent floristic zoning [12], the flora of the East Putorana region was presumably formed in the Upper Pleistocene and, due to relatively stable physiographical conditions, changed very little in the Holocene. In the western part of the plateau (to the west of the general watershed of the Pyasina, Yenisei and Khatanga basins), glaciation lasted longer and partially persists to this day, as can be judged by the preserved forms of glacial relief. The vegetation cover was also significantly affected by the period of its intensive melting in the Holocene, which was characterized by a sharp increase in erosion-accumulative processes. In the eastern part of the plateau, the last glaciation was weaker and has now completely disappeared and almost did not affect the flora and vegetation of this part of the plateau.

\section{References}

1. Flora Putorana: Materials for the knowledge of the peculiarities of the composition and genesis of mountain subarct. flora of Siberia (Novosibirsk, Nauka, 1976)

2. V. B. Kuvaev, Altitudinal distribution of plants in the Putorana Mountains. (USSR AS, Bot. Inst., Leningrad, USSR, 1980)

3. L. L. Zanocha, Botanical J., 87(8) (2002)

4. Ju. P. Kozhevnikov, Mountain phytocenotic systems of the Subarctic (Bot. Inst. ASUSSR, Lenimgrad, 1986)

5. Z. A. Janchenko, Botanical. J, 94(7) (2009)

6. V. N. Uhacheva, Ju. P. Kozhevnikov, Botanical J., 72(5) (1987)

7. E. B. Pospelova, I. N. Pospelov, V. G. Strekalovskaja, Turczaninowia, 20(4) (2017)

8. I. N. Pospelov, E. B. Pospelova, Floral finds on the Putorana plateau (to be published)

9. S. K. Cherepanov, Vascular plants of Russia and neighboring states (within former USSR) (Mir and Family, St. Petersburg, 1995)

10. B. A. Yurtzev, Komarovskie readings of the Academy of Sciences of the USSR. Botanical Institute named after V. L. Komarova, 19 (1966)

11. D. Yu. Bolyshkanov, Passive glaciation of the Arctic and Antarctica (St. Petersburg, AARI, 2006)

12. E. B. Pospelova, I. N. Pospelov, Bull. Udmurt Univer., Biology, Earth Scienc., 26(2) (2016) 